Table. Outcomes at OLE Wk 60 (Wk 108 total)

\begin{tabular}{|c|c|c|c|c|c|c|}
\hline & \multicolumn{2}{|c|}{$\mathrm{BKZ} 160 \mathrm{mg}$ [a] $(\mathrm{N}=82)$} & \multicolumn{2}{|c|}{ BKZ $320 \mathrm{mg}$ [a] $(\mathrm{N}=41)$} & \multicolumn{2}{|c|}{ BKZ total $(\mathrm{N}=123)$} \\
\hline & OC & NRI & OC & NRI & OC & NRI \\
\hline \multicolumn{7}{|l|}{ Efficacy (FAS) n (\%) } \\
\hline ACR20 & $53 / 62(85.5)$ & $53(64.6)$ & 29/37 (78.4) & $29(70.7)$ & 82/99 (82.8) & $82(66.7)$ \\
\hline ACR50 & 41/62 (66.1) & $41(50.0)$ & 25/37 (67.6) & $25(61.0)$ & 66/99 (66.7) & 66 (53.7) \\
\hline ACR70 & $34 / 62(54.8)$ & 34 (41.5) & 19/37 (51.4) & 19 (46.3) & $53 / 99$ & 53 (43.1) \\
\hline BSA 0\% [b] & $35 / 42(83.3)$ & - & $14 / 23(60.9)$ & - & $49 / 65(75.4)$ & - \\
\hline MDA [c] & 43/61 (70.5) & $43(52.4)$ & 20/35 (57.1) & $20(48.8)$ & 63/96 (65.6) & $63(51.2)$ \\
\hline Dactylitis resolution & - & $16 / 27(59.3)$ & - & $11 / 14(78.6)$ & - & $27 / 41(65.9)$ \\
\hline Enthesitis resolution [c] & - & $34 / 45(75.6)$ & - & $19 / 23(82.6)$ & - & $53 / 68(77.9)$ \\
\hline $\begin{array}{l}\text { Safety (SS) } \\
\mathrm{n}(\%) \text { [EAER] }\end{array}$ & \multicolumn{2}{|r|}{$\begin{array}{l}\text { BKZ } 160 \mathrm{mg} \text { [d] } \\
\quad(\mathrm{N}=198)\end{array}$} & \multicolumn{2}{|r|}{$\begin{array}{l}\mathrm{BKZ} 320 \mathrm{mg}[\mathrm{d}] \\
\quad(\mathrm{N}=80)\end{array}$} & \multicolumn{2}{|c|}{$\begin{array}{l}\text { BKZ total }[\mathrm{d}, \mathrm{e}] \\
\quad(\mathrm{N}=204)\end{array}$} \\
\hline Any TEAE & \multirow{2}{*}{\multicolumn{2}{|c|}{$\begin{array}{c}163(82.3)[160.9] \\
17(8.6)\end{array}$}} & \multirow{2}{*}{\multicolumn{2}{|c|}{$\begin{array}{c}57(71.3)[299.8] \\
1(1.3)\end{array}$}} & \multicolumn{2}{|c|}{$179(87.7)[181.1]$} \\
\hline $\begin{array}{l}\text { Study discontinuation due } \\
\text { to TEAEs }\end{array}$ & & & & & & \\
\hline $\begin{array}{l}\text { Permanent withdrawal of } \\
\text { study drug due to TEAEs }\end{array}$ & \multicolumn{2}{|r|}{$16(8.1)$} & \multicolumn{2}{|r|}{$2(2.5)$} & \multirow{2}{*}{\multicolumn{2}{|c|}{$18(8.8)$}} \\
\hline Drug-related TEAEs & \multirow{2}{*}{\multicolumn{2}{|c|}{$\begin{array}{c}72(36.4) \\
19(9.6)[4.8]\end{array}$}} & \multicolumn{2}{|r|}{$29(36.3)$} & & \\
\hline Serious TEAEs & & & \multicolumn{2}{|r|}{0} & \multicolumn{2}{|c|}{$19(9.3)[4.1]$} \\
\hline
\end{tabular}

[a] BKZ $160 \mathrm{mg}$ pts received this dose continuously to Wk 108 (includes those originally assigned to $160 \mathrm{mg}$ with LD); BKZ $320 \mathrm{mg}$ pts were dose-reduced to $160 \mathrm{mg}$ at OLE entry; [b] Pts with BSA $\geq 3 \%$ at BL; [c] Data from OLE Wk 72 (Wk 120 total); [d] Dose received at TEAE onset (pts may be counted in multiple columns); [e] Includes pt time on BKZ 16 mg. EAER: exposure-adjusted event rate; NRI: non-responder imputation; OC: observed case.

Consultant of: UCB Pharma, Amgen, AbbVie, Lilly, Pfizer, Novartis, Gilead, Janssen

DOI: 10.1136/annrheumdis-2020-eular.1850

\section{SAT0404 INCIDENCE OF PSORIATIC ARTHRITIS FROM 2000-2017: A POPULATION-BASED STUDY}

P. Karmacharya ${ }^{1}$, C. S. Crowson ${ }^{2}$, D. Bekele ${ }^{1}$, S. Achenbach ${ }^{2}$, J. M. Davis III $^{1}$, A. Ogdie ${ }^{3}$, A. Duarte-Garcia ${ }^{1}$, H. Maradit-Kremers ${ }^{2}$, M. Tollefson ${ }^{4}$, F. C. Ernste ${ }^{1}, \mathrm{~K}$. Wright ${ }^{1} .{ }^{1}$ Mayo Clinic, Division of Rheumatology, Rochester, United States of America; ${ }^{2}$ Mayo Clinic, Department of Health Sciences Research, Rochester, United States of America; ${ }^{3}$ Hospital of the University of Pennsylvania, Division of Rheumatology, Philadelphia, United States of America; ${ }^{4}$ Mayo Clinic, Department of Dermatology, Rochester, United States of America

Background: Psoriatic arthritis (PsA) is a chronic inflammatory musculoskeletal disease with an estimated prevalence of $0.05 \%$ to $0.25 \%$ in the population and $6 \%$ to $41 \%$ in psoriasis patients. There is disparity in the reported incidence patterns in the general population in more recent years, with increasing incidence seen in Denmark, but relatively stable rates seen in Canada. However, no studies in the US have looked at the recent incidence patterns, and it would be important to see how newer therapies for psoriasis have impacted the incidence of PsA. Variability in the estimates of incidence and prevalence across different studies has been attributed to differences in case ascertainment and most studies have used ICD codes to identify PsA patients.

Objectives: To determine the annual incidence of PsA (2000-17) and compare it to incidence of PsA in previous years $(1970-1999)^{1}$ in the Olmsted County, Minnesota, USA population.

Methods: A retrospective, population-based cohort of PsA patients $\geq 18$ years of age from Olmsted County, MN meeting ClASsification of Psoriatic ARthritis (CASPAR) criteria for PsA (2000-17) was identified from the Rochester Epidemiology Project (REP). REP ensures virtually complete ascertainment and follow-up of all clinically diagnosed cases of PsA in a geographically-defined area. The date of fulfillment of CASPAR criteria was taken as the PsA incidence date. Age- and sex-specific incidence rates, adjusted to 2010 US white population, were reported. Our previously reported cohort from REP (19701999) ${ }^{1}$ also used the same CASPAR criteria, and trends from the current study were compared to the previous years.

Results: There were 170 incident cases of PsA, with a mean age of 46.7 $(S D=12.3)$ years and $47 \%$ females from $2000-17$. The overall age and sex adjusted annual incidence of PsA per 100,000 population was $8.8(95 \% \mathrm{Cl}$ 7.5-10.1), and higher in males $(9.7,95 \% \mathrm{Cl} 7.7-11.7)$ than females $(8.0,95 \%$ $\mathrm{Cl}$ 6.2-9.8). Overall incidence was highest in the age range 40-59 years (Table 1). The incidence rate was relatively stable in the recent years 20002017 compared to $1970-1999^{1}$ where a rise in incidence was observed (3.6 to 9.8 per 100,000 persons from $1970-79$ to $1990-99$, $p<0.001$ ) (Figure 1).
Table 1. Annual incidence rate, IR (per 100,000) of psoriatic arthritis by age and sex between 2000-17 in Olmsted County, MN.

\begin{tabular}{|c|c|c|c|c|c|c|}
\hline \multirow[b]{2}{*}{ Age Group, yrs } & \multicolumn{2}{|r|}{ Male } & \multicolumn{2}{|r|}{ Female } & \multicolumn{2}{|r|}{ Total } \\
\hline & $\mathrm{N}$ & IR & $\mathrm{N}$ & IR & $N$ & Rate \\
\hline $18-29$ & 9 & 4.1 & 4 & 1.6 & 13 & 2.8 \\
\hline $30-39$ & 24 & 13.4 & 14 & 7.3 & 38 & 10.2 \\
\hline $40-49$ & 24 & 13.9 & 26 & 14.0 & 50 & 14.0 \\
\hline $50-59$ & 21 & 13.5 & 28 & 16.2 & 49 & 14.9 \\
\hline $60-69$ & 7 & 6.9 & 8 & 7.1 & 15 & 7.0 \\
\hline $70-79$ & 3 & 5.0 & 0 & 0.0 & 3 & 2.2 \\
\hline $80+$ & 2 & 6.0 & 0 & 0.0 & 2 & 2.2 \\
\hline Total $(95 \% \mathrm{Cl})$ & 90 & $9.7(7.7-11.7) \dagger$ & 80 & $8.0(6.2-9.8) \dagger$ & 170 & $8.8(7.5-10.1) \dagger \dagger$ \\
\hline
\end{tabular}

† Age-adjusted to the 2010 US White population. †† Age- and sex-adjusted to the 2010 US White population

Conclusion: In the Olmsted County population, the increasing PsA incidence seen in previous years $1970-1999^{1}$ seems to have leveled off after 2000 . This is in contrast to increasing incidence in recent years reported from Denmark, Taiwan and Israel. However, similar to our study, incidence rates for PsA from 2008-2015 were reported to be stable in Canada.

\section{References:}

[1] Wilson FC, Icen M, Crowson CS, McEvoy MT, Gabriel SE, Kremers HM Time trends in epidemiology and characteristics of psoriatic arthritis over 3 decades: a population-based study. J Rheumatol. 2009;36(2):361-367.

Acknowledgments: This project was supported by CTSA Grant Number UL1 TR002377 from the National Center for Advancing Translational Science (NCATS).

Disclosure of Interests: Paras Karmacharya: None declared, Cynthia S. Crowson Grant/research support from: Pfizer research grant, Delamo Bekele: None declared, Sara Achenbach: None declared, John M Davis III Grant/research support from: Research grants from Pfizer, Consultant of: Served on advisory boards for Abbvie and Sanofi-Genzyme, Alexis Ogdie Grant/research support from: Pfizer, Novartis, Consultant of: Abbvie, Amgen, BMS, Celgene, Corrona, Janssen, Lilly, Pfizer, Novartis, Ali Duarte-Garcia: None declared, Hilal Maradit-Kremers: None declared, Megha Tollefson: None declared, Floranne C. Ernste: None declared, Kerry Wright: None declared DOI: 10.1136/annrheumdis-2020-eular.2190

\section{SAT0405 CLINICAL AND PSYCHOLOGICAL PREDICTORS OF GASTROINTESTINAL INTOLERANCE TO METHOTREXATE IN PATIENTS WITH PSORIATIC ARTHRITIS}

G. Natalello ${ }^{1}$, E. De Lorenzis ${ }^{1}$, G. Tanti ${ }^{1}$, P. Rubortone ${ }^{1}$, M. R. Magurano ${ }^{2}$, G. Peluso ${ }^{3}$, E. Gremese ${ }^{1,3} \cdot{ }^{1}$ Catholic University of the Sacred Heart, Institute of Rheumatology, Rome, Italy; ${ }^{2}$ Fondazione Policlinico Universitario A. Gemelli IRCCS, Department of Psychology, Rome, Italy; ${ }^{3}$ Fondazione Policlinico Universitario A. Gemelli IRCCS, Department of Rheumatology, Rome, Italy

Background: Methotrexate (MTX) is a first-line treatment for psoriatic arthritis (PsA). Gastrointestinal intolerance (GI) to the drug is a common adverse event 
that limits its use and can be mediated by autonomic dysfunction or classical conditioning phenomena to repeated drug exposure. Anxiety and depression could promote these processes.

Objectives: To assess the prevalence of GI to MTX and its association with anxiety and depression in PsA patients.

Methods: One hundred unselected PsA patients in stable MTX treatment were characterized by disease characteristics, adherence to treatment by Morisky Medication Adherence Scale (MMAS-8) and comorbidity by Rheumatic Disease Comorbidity Index (RDCI). Depressive and anxious symptoms were assessed by Hospital Anxiety and Depression Scale (HADS). The presence and the severity of nausea, vomiting, abdominal pain and diarrhoea after administration (associative symptoms) and just before or even at the thought of taking MTX (anticipatory symptoms) were recorded.

Results: Patients had a mean age of $56.9 \pm 12.0$ years and a disease duration of 9.5 years (0.1-58.0 years). They were male, smokers and overweight in $40.0 \%$, $20.0 \%$ and $65.0 \%$ of cases, respectively. The prevalence of both significant anxious and depressive symptoms was $42.0 \%$. DAPSA showed remission, low disease activity (LDA), moderate disease activity (MDA) and high disease activity (HDA) in $24.0 \%, 41.0 \%, 32.0 \%$ and $3.0 \%$ of patients, respectively. MTX was taken orally by $15.0 \%$ of patients and associated with another conventional or biological DMARD in $14.0 \%$ and $35.0 \%$ of cases, respectively. Symptoms of GI to MTX were complained by $69.3 \%$ of patients. Specifically, the prevalence of nausea, diarrhea, vomiting and abdominal pain was $59.0 \%, 23.0 \%, 21.0 \%$ and $30.0 \%$ with associative pattern and $43.0 \%, 12.0 \%, 10.0 \%$ and $16.0 \%$ with anticipatory pattern, respectively. Patients with anxious symptoms experienced more frequently moderate to severe associative nausea $(71.4 \%$ vs $50.0 \%, p=0.032)$ and abdominal pain ( $42.9 \%$ vs $20.7 \%, p=0.017)$, and anticipatory nausea $(42.9 \%$ vs $19.0 \%, p=0.009)$, vomiting $(14.3 \%$ vs $6.9 \%, p=0.046)$, and abdominal pain $(26.2 \%$ vs $8.6 \%, p=0.018)$ than non-anxious patients. Patients with depressive symptoms more commonly had associative diarrhea ( $33.0 \%$ vs $15.5 \%, p=0.037$ ), with no difference in the prevalence of anticipatory symptoms. The presence of associative and anticipatory nausea was associated with higher anxiety scores ( $p=0.006$ and $p=0.02$ respectively) without differences in the depression score. Associative nausea characterized younger patients $(p=0.001)$, female $(p=0.02)$, with lower BMI $(p=0.02)$ and treated with higher MTX doses $(p=0.05)$. Anticipatory nausea was associated with a lower age $(p=0.02)$, a lower BMI $(p=0.005)$, a longer disease duration $(p=0.028)$, a lower DAPSA $(p=0.02)$, an higher MTX doses $(p=0.02)$ and a lower comorbidity burden $(p=0.03)$. The anticipatory and associative nausea determined lower compliance according to MMAS-8 $(p=0.007$ and $p=0.001$, respectively). An anxious profile characterized patients with moderate to severe associative nausea also in the logistic regression model corrected for age ( $\geq 65$ years), gender, BMI $(\geq 25 \mathrm{~kg} / \mathrm{m} 2)$ and MTX dose ( $\geq 0.2 \mathrm{mg} / \mathrm{kg} /$ week) (OR 3.0, IC 1.1-8.4, $\mathrm{p}=0.036$ ), and patients with anticipatory nausea also in the model corrected for age ( $\geq 65$ years), gender, BMI $(\geq 25 \mathrm{~kg} / \mathrm{m} 2)$ and MTX dose ( $\geq 0.2 \mathrm{mg} / \mathrm{kg} /$ week) and disease duration ( $\geq 6$ years) (OR 3.0, IC 1.1-8.0, $p=0.027$ ). Conclusion: Up to two-thirds of patients with PsA who have been treated with MTX experienced symptoms of GI, leading to reduced therapeutic adherence. Associative and anticipatory symptoms characterize patients with a specific clinical and psychological profile.

Disclosure of Interests: Gerlando Natalello: None declared, Enrico De Lorenzis: None declared, Giacomo Tanti: None declared, Pietro Rubortone: None declared, Maria Rosaria Magurano: None declared, Giusy Peluso: None declared, Elisa Gremese Consultant of: AbbVie, Bristol-Myers Squibb, Celgene, Eli Lilly, Janssen, Merck Sharp \& Dohme, Novartis, Sanofi, UCB, Roche, Pfizer, Speakers bureau: AbbVie, Bristol-Myers Squibb, Celgene, Eli Lilly, Janssen, Merck Sharp \& Dohme, Novartis, Sanofi, UCB, Roche, Pfizer DOI: 10.1136/annrheumdis-2020-eular.2560

\section{SAT0406 \\ THE ASSOCIATION BETWEEN PERIPHERAL ENTHESITIS SCORES AND NAILFOLD VIDEOCAPILLAROSCOPY FINDINGS IN PATIENTS WITH PSORIATIC ARTHRITIS}

P. Bora Karsli ${ }^{1}$, N. Guven ${ }^{1}$, I. Sunar ${ }^{2}$, Ş. Ataman ${ }^{1} .{ }^{1}$ Ankara University, Department of Rheumatology, Department of PMR, Ankara, Turkey; ${ }^{2}$ Aydin, Ataturk Public Hospital, Department of Rheumatology, Department of PMR Aydın, Turkey

Background: Enthesitis is one of the key feature of psoriatic arthritis (PsA), it is usually overlooked in the asymptomatic patients. Nail disease often precedes PSA and nailfold videocapillaroscopy (NVC) is a useful technique for evaluating changes in microcirculation of nail that is considered to play an important role for early detection of enthesitis and PsA [1-4].

Objectives: To investigate the link between NVC findings and severity of peripheral enthesitis scores in patients with PsA.

Methods: In this cross-sectional single center study, 34 consecutive PsA patients and as control group (healthy controls - HC), 22 subjects without rheumatic diseases were involved. Psoriasis area severity index (PASI) was used to express severity of psoriasis (Ps) and percentage of affected area. Leeds enthesitis index (LEI) comprised assesment of lateral epicondyles of humerus, medial condyles of femur, and the insertion of the Achilles tendon. Madrid Sonographic Enthesitis Index (MASEI) was applied to quantify the extent of sonographic entheseal abnormalities. MASEI-inflammatory, MASEI-damage and as a sum of these MASEI-total scores were recorded. NVC was performed on eight fingers in each subject.

Results: We enrolled 34 patients with PsA (median age=47.74 years, median disease duration $=6.91$ years) and $22 \mathrm{HC}$ (median age $=46.77$ years). There were no significant differences between two groups concerning age, gender distribution and body mass index. Ps and PsA disease duration in terms of years were not correlated with MASEI and NVC scores. PASI score associated with MASEI-inflammatory score $(r=0.40, p=0.01)$. There were significant correlation between the NVC score and MASEl-inflammatory $(r=0.53, p=0.001)$ and MASEl-total scores ( $r=0.35, p=0.04)$ (Table 1). No association was found between LEI and NVC scores ( $p=0.34)$. MASEI enthesitis and NVC scores were significantly higher in the patient group $(p=0.00)$.

Table 1. Correlation between the capillaroscopy findings and MASEIinflammatory and MASEI-total scores in patients with psoriatic arthritis

\begin{tabular}{lcc}
\hline \multirow{2}{*}{ MASEI } & \multicolumn{2}{c}{ Capillaroscopy } \\
\cline { 2 - 3 } & PSA & HC \\
\hline MASEI-inflammatory & & \\
$r$ & $0.53^{\star \star}$ & 0.7 \\
$p$ & 0.001 & 0.75 \\
MASEI-total & & \\
$r$ & $0.35^{\star}$ & 0.19 \\
$p$ & 0.04 & 0.38
\end{tabular}

Spearman's Correlation Coefficient; ${ }^{* *}$ Correlation is significant at the 0.01 level (2-tailed), * Correlation is significant at the 0.05 level (2-tailed).

$p<0.05$ statistic significance

MASEI: Madrid Sonographic Enthesitis Index, PsA: psoriatic arthritis, HC: healthy controls

Conclusion: NVC may objectively reflect the peripheric enthesopathy severity and give opportunity for early diagnosis of PsA.

References:

[1] Kaeley, Gurjit S., et al. "Enthesitis: a hallmark of psoriatic arthritis." Seminars in arthritis and rheumatism. Vol. 48. No. 1. WB Saunders, 2018.

[2] Ash, Zoe R., et al. "Psoriasis patients with nail disease have a greater magnitude of underlying systemic subclinical enthesopathy than those with normal nails." Annals of the Rheumatic Diseases 71.4 (2012): 553-556.

[3] Smith, Vanessa, et al. "Nailfold capillaroscopy and clinical applications in systemic sclerosis." Microcirculation 23.5 (2016): 364-372.

[4] Ribeiro, Camila Ferrari, et al. "Periungual capillaroscopy in psoriasis." Anais brasileiros de dermatologia 87.4 (2012): 550-553.

Disclosure of Interests: None declared

DOI: 10.1136/annrheumdis-2020-eular.2811

\begin{tabular}{|l|l}
\hline SAT0407 & FOLLOW-UP EXAMINATION FOR THE DETECTION \\
& OF POTENTIAL PSORIATIC ARTHRITIS BY \\
& FLUORESCENCE OPTICAL IMAGING - IN \\
& COMPARISON TO MUSCULOSKELETAL ULTRASOUND
\end{tabular}

J. Büttner ${ }^{1}$, A. M. Glimm¹ , G. Kokolakis ${ }^{2}$, M. Erdmann-Keding ${ }^{2}$, G.

R. Burmester ${ }^{1}$, J. Klotsche ${ }^{3,4}, \mathrm{~S}$. Ohrndorf ${ }^{1} .{ }^{1}$ Charité - Universitätsmedizin Berlin, Department of Rheumatology and Clinical Immunology, Berlin, Germany; ${ }^{2}$ Charité - Universitätsmedizin Berlin, Department of Dermatology, Venerology and Allergology, Berlin, Germany; ${ }^{3}$ German Rheumatism Research Centre (DRFZ) Berlin, Berlin, Germany; ${ }^{4}$ Charité - Universitätsmedizin Berlin, Institute for Social Medicine, Epidemiology and Health Economics, Berlin, Germany

Background: Up to $30 \%$ of all plaque-type psoriasis patients develop psoriatic arthritis (PsA) (1). Early diagnosis of PsA can be difficult due to its heterogenous manifestation and the lack of disease- specific biomarkers, but it is crucial for disease outcome. Recently, our group has shown that fluorescence optical imaging (FOI) can be a helpful diagnostic tool for early PsA diagnosis since it can differentiate between patients with confirmed PsA and suspected PsA (2).

Objectives: To follow-up patients by FOI with confirmed and suspected PsA with special focus on the group of patients in which PsA could be confirmed between baseline and follow-up - and to compare with the findings of musculoskeletal ultrasound (US).

Methods: Patients included in our previous study (1) were re-evaluated by FOI of both hands in a standardized manner using the predefined phases 1-3 (p1-p3) and the PrimaVistaMode (PVM). US in greyscale (GS) and power Doppler (PD) were performed of the clinically dominant hand (for tenderness and/or swelling) 